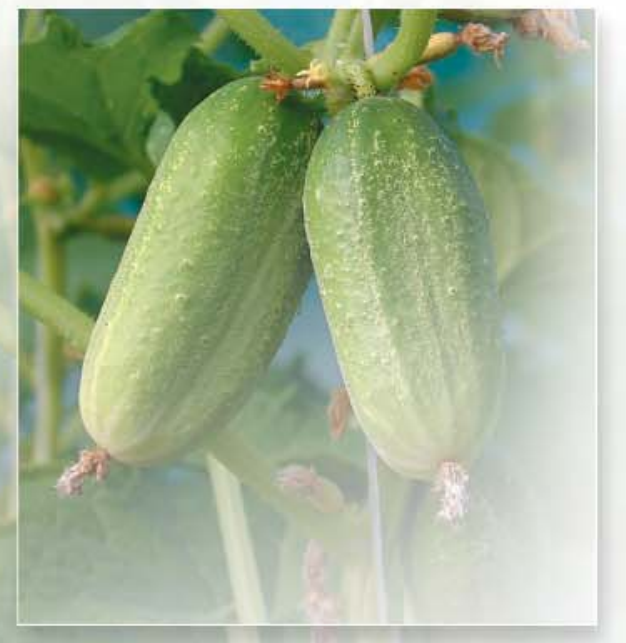

\title{
КАЧЕСТВО ПЛОДОВ ОГУРЦА В ЗАВИСИМОСТИ ОТ УСЛОВИЙ ВЫРАЩИВАНИЯ
}

Бочаров В.Н. - кандидат с. -х. наук,

зав. отделом системно-энергетического подхода к оиенке технологии возделывания сельскохозяйственных культур соколова Г.Ф. - кандидат с. -х. наук,

зав. сектором природопользования

киселева Н.Н. - кандидат с. -х. наук, ст.н.с.

Ворониова А.И. - М.Н.С.

ГнУ Всероссийский научно-исследовательский институт орошаемого овомеводства и бахчеводства

416341 Астраханская область, г. Камызяк, ул. Любича, 16

Тел.: +7 (85145) 95-9-07

E-mail:vniiob@kam.astranet.ru

На качество плодов огурца оказывают влияние способы и условия их вырачивания: открымый и защищенныи грунт; сроки, дозы внесения минеральных удобрений и орочение.

ключевые слова: огуреи, нитраты, капельный полив.

о всех почвенно-климатических зонах нашей страны продуктивность овощных культур практически лимитируется недостатком влаги и элементов минерального питания. Поэтому в комплексе агротехнических приёмов, обеспечивающих получение запланированной урожайности, система удобрения и режим орошения занимают видное место.

Система удобрения овощных культур включает в себя применение оптимальных доз и форм минеральных удобрений, а также лучшие сроки и способы их внесения. От сроков, способов внесения и равномерного распределения элементов минерального питания между растениями зависит эффективность применения удобрений. Однако только сбалансированные удобрения с учётом биологических особенностей растений и почвенно-климатических факторов создадут благоприятные условия для получения более высокой урожайности сельскохозяйственных культур при хорошем качестве продукции.

Многие исследователи отмечают, что внесение минеральных удобрений в несколько приёмов при возделывании овощных культур не имело преимуществ по сравнению с единовременным внесением всей дозы. Продуктивность культур оставалась на одном уровне даже в тех случаях, когда дробное внесение удобрений в виде подкормок приурочивали к критическим фазам развития растений, когда они наиболее требовательны к условиям минерального питания.

Быстро растущее огуречное растение отличается высоким уровнем потребления минеральных элементов из почвы. Поэтому очень важно обеспечить его достаточным количеством усвояемой пищи сразу же после появления всходов. Ершовой В.Л. (1970) установлено, что минеральные удобрения целесообразно вносить в один приём до посева, так как дробное внесение их не увеличивало урожайность.

Значительную роль при возделывании овощных культур приобретают азотные удобрения. При достаточном снабжении растений всеми элементами минерального питания азот активно участвует в синтезе органического вещества, увеличивая прирост как вегетативной, так и продуктивной части растений.

Исследованиями Патрона П.И. (1981) подтверждаются результаты научных работ других учёных в том, что подкормки не способствуют увеличению урожайности огурца в отношении фосфорных и калийных удобрений, а также азотных, если они применяются в небольших дозах (60-90 кг/га д.в.). При более высоких дозах азотных удобрений, часть их следует вносить в подкормках.
Результаты полевых опытов в почвенноклиматических условиях дельты Волги показали, что различные способы внесения азотных удобрений, как одноразовое (основное) в дозе $\mathrm{N}_{120}$, так и дробное $\left(\mathrm{N}_{70}\right.$ под основное +2 подкормки по $\mathrm{N}_{25}$ ) на фосфорно-калийном фоне $\mathrm{P}_{135} \mathrm{~K}_{60}$ поразному влияли на рост, развитие и продуктивность растений огурца районированного сорта Резастр при капельном орошении. Применение двух азотных подкормок по $\mathrm{N}_{25}$ при основном внесении удобрений в дозе N70P135K60 и поддержание влажности почвы при 80-90\% HВ способствовали более мощному наращиванию листостебельной массы. Площадь ассимиляционного аппарата увеличивалась с 27 тыс. м²/га при однократном до 35 тыс. м²/га при дробном внесении азотных удобрений.

Азот с успехом использовался растениями огурца сорта Резастр как при внесении всей нормы удобрений до посева, так и при перенесении части их в подкормки. Однако более высокая урожайность товарных плодов (44 т/га) отмечалась при двух азотных подкормках по $\mathrm{N}_{25}$ на основном фоне $\mathrm{N}_{70} \mathrm{P}_{135} \mathrm{~K}_{60}$. В то же время, при однократном (основном) внесении азотных удобрений $\mathrm{N}_{120}$ на фосфорно-калийном фоне Р135К60 она составила 38 т/га, а без удобрений - 29 т/га (рис.1). 


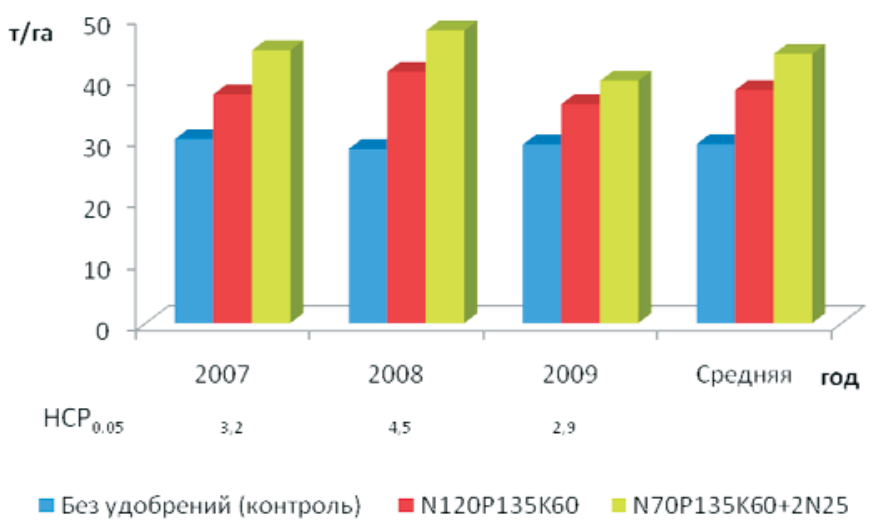

Рис. 1. Урожайность огурца в зависимости от сроков внесения удобрений, т/га (2007-2009 годы)

Оценивая качество произведённой овощной продукции, в первую очередь, обращают внимание на её структуру: стандарт, нестандарт. Согласно ГОСТ 1726-85 для свежих огурцов стандартные плоды должны быть целыми, зелёной окраски, без загрязнений и механических повреждений. В зависимости от сорта определяется стандартность плода по размеру. Так, у короткоплодных сортов зеленцы первой группы не должны превышать в длину 11 см, второй - 14 см. Такие плоды, обеспечивая высокую товарность урожая, дают сортообразцы
Журавлёнок, Будь Здоров, Герман, Кристина, Резастр, Феникс, Альтаир.

Плоды огурца начинают свой рост сразу после оплодотворения яйцеклеток и, в основном, это происходит ночью, когда в листьях идёт распад сложных органических веществ и отток продуктов их распада в плоды. При этом плоды огурца растут за счёт растягивания клеток мякоти, так как деление прекращается ещё в фазе завязи (Филов, 1941). В результате, клетки у пикулей и корнишонов различных сортов приблизительно одинаковы. Они имеют многоугольную форму и тесно прилегают друг к другу, не оставляя межклеточных пространств. Такая структура обеспечивает плодам при консервировании хрустящую мякоть, как у свежих. Сор- товые различия начинают проявляться в более позднем возрасте - при переработке плодов в фазе зеленца, длиною более 9 см.

Однако кроме размера необходимо определять и биохимические качества плодов (содержание сухого вещества, суммы сахаров, витаминов, наличие нитратов и других показателей), которые во многом определяются сортовыми особенностями, почвенно-климатическими и агротехническими факторами.

От размера (возраста) плодов в значительной степени зависит химический состав плодов огурца. Наибольшее содержание сухого вещества $(6,68 \%)$ и витамина C (13,56 мг\%) отмечалось у пикулей (3-5 см). Повышенное количество растворимых сахаров наблюдалось в корнишонах 1 и 2 группы (5, 1-7,0 и 7,1-9,0 см). Плоды уродливой формы по химическому составу приближаются к плодам фракций 9,1-14 см. Поскольку химический состав в значительной степени определяет пищевую ценность и технологические качества плодов, то требуется тщательная сортировка продукции на фракции в зависимости от её назначения (табл. 1).

\section{1. Химический состав плодов огурца в зависимости от их размера (2007-2009 годы)}

\begin{tabular}{|c|c|c|c|}
\hline Длина плодов, см & Сухое вещество, \% & Сумма сахаров, $\%$ & Витамин С, мг\% \\
\hline $3,0-5,0$ & 6,68 & 1,59 & 13,56 \\
\hline $5,1-7,0$ & 6,06 & 2,14 & 9,41 \\
\hline $7,1-9,0$ & 5,25 & 2,17 & 7,93 \\
\hline $9,1-12,0$ & 4,82 & 2,00 & 6,57 \\
\hline $12,1-14,0$ & 4,80 & 1,82 & 5,58 \\
\hline Уродливой формы & 4,79 & 1,78 & 6,38 \\
\hline
\end{tabular}
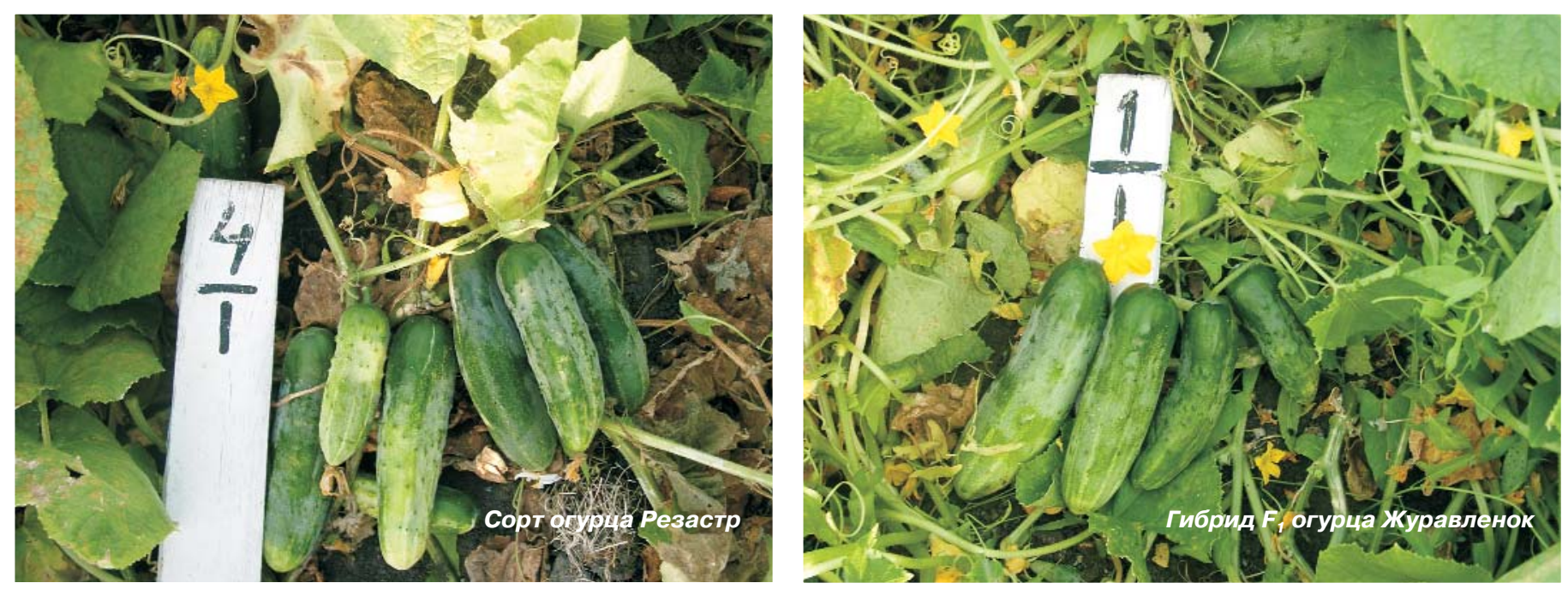
Поэтому крупные и мелкие плоды не рекомендуется принимать в одной партии, поскольку они перерабатываются в разных условиях на различные готовые продукты при консервировании. Да и цены на корнишоны значительно более высокие, чем на зеленцы. В результате, производителям невыгодно реализовывать плоды разных фракций все вместе.

Существенное влияние на химический состав плодов огурца оказывает способ их выращивания: в открытом или защищённом грунте. Качество плодов из открытого грунта значительно выше, чем из защищенного. Так, в плодах, выращенных в открытом грунте, по сравнению с полиэтиленовыми укрытиями больше содержалось: сухого вещества - на 10\%, растворимых сахаров на 5\%, аскорбиновой кислоты на 65\%. Та же прибавка по сухому веществу и сумме сахаров наблюдалась при сравнении плодов из открытого грунта с плодами из остеклённых теплиц, только витамина С было больше на 19\% (Сокол, 1978).

Наибольшая урожайность товарных плодов огурца была достигнута при внесении минеральных удобре- ний в дозе $\mathrm{N}_{60} \mathrm{P}_{90} \mathrm{~K}_{90}$ на выщелоченном чернозёме Украины. Плоды с делянок этого варианта были хорошего качества, как в свежем, так и солёном виде. В свежих плодах увеличивалось содержание сухого вещества на 0,4\%, сахаров - на 0,1\%, аскорбиновой кислоты - на 2,2 мг\% по сравнению с контролем (без удобрений).

Плоды более высокого качества можно получить при применении минеральных удобрений с орошением. Так, на фоне оптимальной влагообеспеченности 80\% НВ с увеличением доз минеральных удобрений улучшались товарные качества и биохимические показатели плодов: повышалось содержание сухого вещества на 1,0\%, сахаров - на 0,12\%, витамина С - на 2,0 мг\% (Сокол, 1970). Плоды огурца, выращенные при орошении, имели типичную форму для сорта, а без полива в структуре собранной продукции содержалось большое количество больных и уродливых плодов.

На качество овощей оказывает влияние их способность аккумулировать нитраты. Огурец занимает среднее положение среди овощных культур по накоплению нитратов в плодах, однако при высоком содержании доступного азота в почве или при нарушении процесса превращения нитратов в аминокислоты иногда в плодах обнаруживается избыток нитратов.

Нитраты являются естественным продуктом жизнедеятельности нитрифицирующих бактерий в почве, они широко распространены в природе, служат главным источником азотного питания растений, основой синтеза белковых соединений и без них невозможно само существование растительного организма. Нитраты возникают при минерализации органического вещества почвы и растительных остатков, органических и азотных удобрений. Они поступают через корневую систему в надземные органы и могут накапливаться в больших количествах без вреда для самих растений в клеточных вакуолях как запасной источник азота. Запасная форма нитратов, накопленных в продуктовых органах овощных культур (кочаны, корнеплоды, плоды) и представляет опасность для человека (Борисов и др., 2003). У каждого культурного растения нитраты скапливаются в определённых местах продуктивной части. Так, в кочанной капусте - это ко-

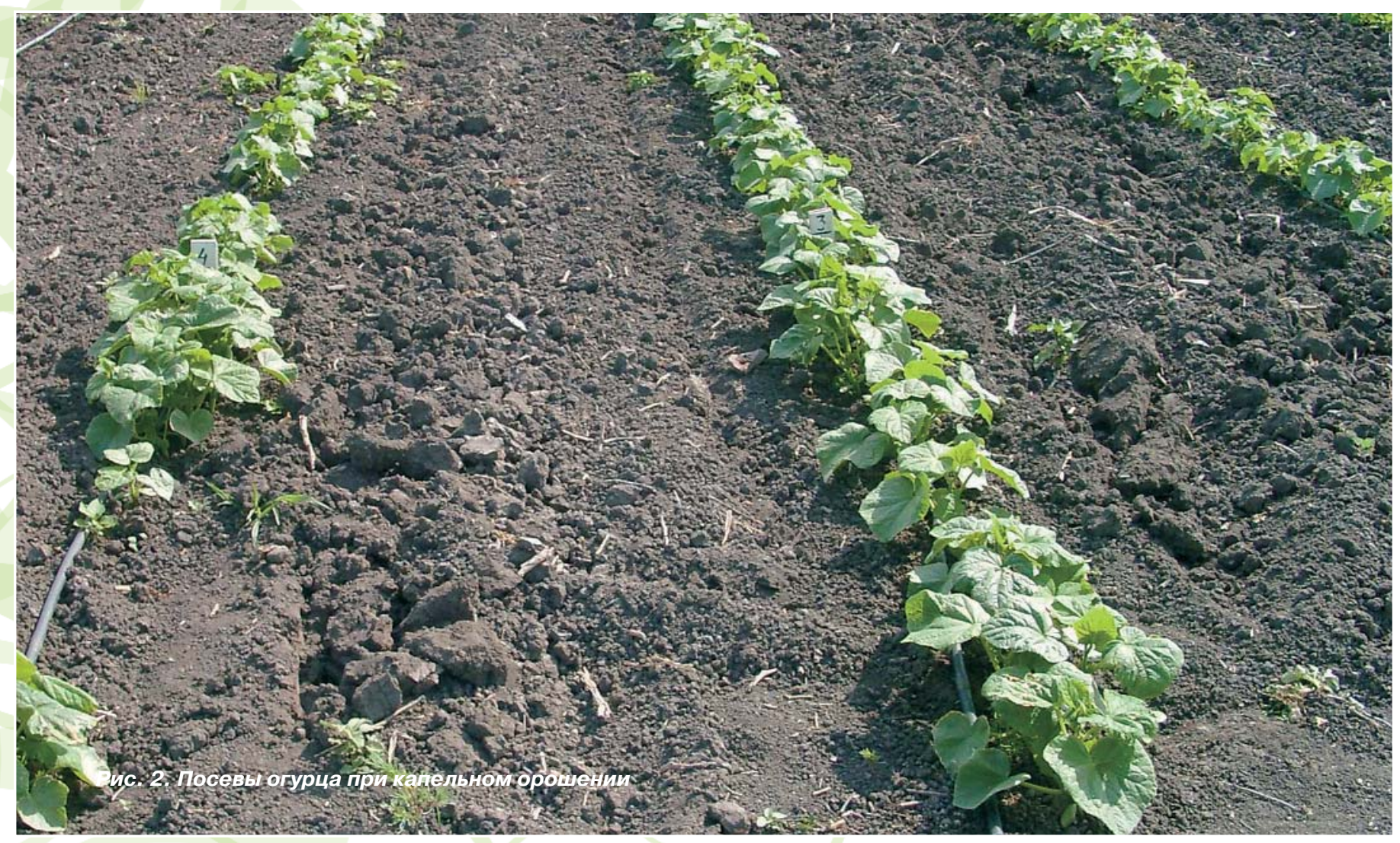


черыга, прожилки исходящие от неё и верхние листья кочана; у тыквенных культур, в том числе у огурца кожура и часть плода у плодоножки. Токсичность нитратов связана с образованием из них нитритов, которые могут вызвать повышенное содержание метагемоглобина в крови человека, особенно опасное для детей. Поэтому при длительном и обильном питании продуктами с повышенным содержанием нитратов могут возникнуть острые отравления. Однако за всю историю медицины не зафиксировано ни одного смертельного случая отравления свежими овощами, так как вред от нитратов блокируется витаминами (Борисов, 1978). С целью контроля качества овощной продукции и охраны здоровья человека Минздрав РФ установил предельно допустимые количества (ПДК) содержания нитратов в плодах огурца, выращенных в открытом грунте - 150 мг/кг и защищённом - 400 мг/кг.

Результаты исследований по влиянию минеральных удобрений на продуктивность овощных культур, возделываемых при капельном орошении, на аллювиально-луговых тяжелосуглинистых почвах дельты Волги показали, что содержание нитратов в плодах огурца сорта Резастр зависело не только от дозы, но и от сроков внесения азотных удобрений. Количество нитратов в плодах увеличивалось с 60 мг/кг в контроле (без удобрений) до 90 мг/кг при одноразовом (основном) внесении $\mathrm{N}_{120} \mathrm{P}_{135} \mathrm{~K}_{60}$ и до $115 \mathrm{мг/кг}$ при двух азотных подкормках по $\mathrm{N}_{25}$ на фоне $\mathrm{N}_{70} \mathrm{P}_{135} \mathrm{~K}_{60}$. Однако это уве-

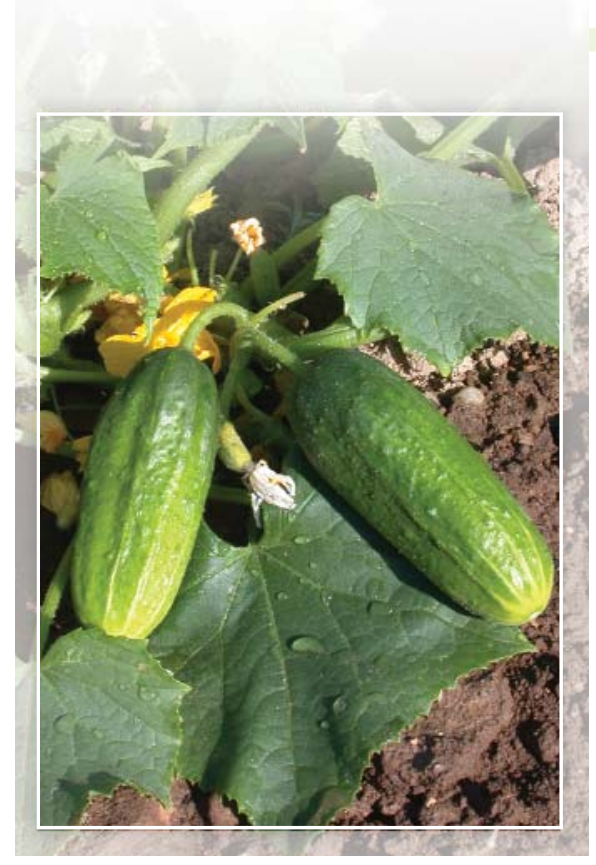

личение не превышало предельно допустимую концентрацию (ПДК 150 мг/Кг).

В условиях обильного азотного питания важную роль в снижении содержания нитратов в растениях играет калий. Калий, повышая активность нитратредуктазы и способствуя синтезу углеводов и органических кислот, оказывает косвенное влияние на интенсивность процессов связывания нитратов в органические соединения (Вендило и др., 1986).

По данным многолетних исследований, применение фосфорных удобрений практически не влияло на содержание нитратов, а калийные туки существенно снижали их количество в овощах. Отсутствие калия в составе минеральных удобрений $\left(\mathrm{N}_{60} \mathrm{P}_{90}\right)$ приводило к нарушению соотношения питательных элементов в почве и растениях, что вело к накоплению нитратов в плодах огурца (172 мг/кг). В то же время присутствие калия в составе полного удобрения $\left(\mathrm{N}_{60} \mathrm{P}_{90} \mathrm{~K}_{60}\right)$ обеспечивало повышение урожайности огурца при заметном снижении содержания нитратов (137 мг/кг).

Уровень нитратов в плодах огурца в период вегетации снижается от первого сбора к последнему в 1,21,4 раза. Пикули (5,0-7,0 см) накапливают нитратов в 1,2-1,6 раза больше по сравнению с зеленцами (9,1-14,0 см), при этом их содержание превышает ПДК. Поэтому пикули и корнишоны следует использовать для промпереработки или лучше оставлять их на кусте до формирования зеленца. В солёных огурцах нитратный азот распределяется равномерно в плодах и рассоле, что исключает превышение допустимой концентрации.

Снизить содержание нитратов в плодах возможно, если уборку урожая производить во второй половине дня. В это время суток количество нитратов в растениях почти в два раза меньше, чем утром.

Значительно снижается содержание нитратов в готовой продукции при консервировании. Плоды огурца после бланшировки теряют 20\%, а после стерилизации ещё 37\% (Борисов и др., 2003). Кроме этого следует удалять плодоножку с частью кожицы.

\section{תumepamypa}

1. Борисов, В.В. Удобрения овощных культур / В.В. Борисов. - М.: Колос, 1978. - 207 с.

2. Борисов, В.В. Качество и лежкость овощей / В.В. Борисов, С.С. Литвинов, А.В. Романова. - М., 2003. $625 \mathrm{c}$.

3. Вендило, Г.Г. Удобрения овощных культур /Г.Г. Вендило, Т.А. Микенаев, В.Н. Петриченко, А.А. Скаржинский. - М.: Агропромиздат, 1986. - 206 с.

4. Ершова, В.Л. Огурцы /В.Л. Ершова//В кн. «Овощеводство Молдавии». - Кишинёв: Штиинца, 1970. - С. 305-314

5. Патрон, П.И. Комплексное действие агроприёмов в овощеводстве /П.И. Патрон. - Кишинёв.: Штиинца, 1981. - 284 с.
6. Сокол, П.Ф. Рекомендации по повышению качества овощей и плодов бахчевых культур /П.Ф. Сокол. -М.: Колос, 1970. - 30 с.

7. Сокол, П.Ф. Улучшение качества продукции овощных и бахчевых культур /П.Ф. Сокол. - М.: Колос, 1978. - С. 231-240.

8. Толстоусов, В.П. Удобрение и качество урожая / В.П. Толстоусов.- М.: Агропромиздат, 1987.206 c.

9. Филов, А.И. Связь морфологических признаков плодов огурца с его хозяйственно ценными качествами /А.И. Филов//Вестник социалистического растениеводства. - 1941. - №1. 